\title{
Optimization in Site Selection of Wind Turbine for Energy Using Fuzzy Logic System and GIS-A Case Study for Gujarat
}

\author{
Kunal Kumar Borah ${ }^{1,2}$, Souvnik Roy ${ }^{1 *}$, T. Harinarayana ${ }^{1}$ \\ ${ }^{1}$ Gujarat Energy Research and Management Institute (GERMI), Gujarat, India \\ ${ }^{2}$ Centre for Environmental Planning and Technology (CEPT), Gujarat, India \\ Email: *Souvnik.r@germi.res.in
}

Received October 12, 2013; revised November 19, 2013; accepted December 6, 2013

Copyright (C) 2013 Kunal Kumar Borah et al. This is an open access article distributed under the Creative Commons Attribution License, which permits unrestricted use, distribution, and reproduction in any medium, provided the original work is properly cited.

\begin{abstract}
The development of new wind energy project requires studying of many parameters to achieve maximum benefits at the cost of minimum environmental impacts. Using Geographic Information System (GIS), an analytical framework has been developed in this paper with fuzzy logic to evaluate the suitable site for turbines for optimum energy output. The criteria for suitable site for energy optimization are environmental, physical and human factors. The present study helps to assess the appropriate sites for the wind turbines in Gujarat. The result obtained from the study conveys the suitability of the development of wind turbines along the western parts of Gujarat. The suggested model could be used for the future site selection of the wind turbine which in turn could be of orientation for energy planners and decision makers.
\end{abstract}

Keywords: Optimization; Wind Turbine Placement; Geographic Information System; Fuzzy Logic; Fuzzy Sets; Pareto Surface; Multi-Criteria Decision Making

\section{Introduction}

Wind occurs as a result of the unequal distribution with the difference in the temperature and the pressure around the world. The speed and the direction of the wind can be numerous based on the characteristics of the topographies. Implementation of new energy sources from renewable power reduces the dependency on fossil fuels which is the primary concern for many countries. Another important contribution of renewable energy is its high potential in reducing $\mathrm{CO}_{2}$ emissions thereby protecting the environment. Among various renewable energy sources, wind energy is one of the prominent energy sources.

India's cumulative Grid interactive or Grid Tied Renewable Energy Capacity (excluding Large Hydro) has reached $26.9 \mathrm{GW}$, of which $68.9 \%$ comes from wind, while solar PV contributed nearly $4.59 \%$ of the Renewable Energy installed capacity in India [1]. Table 1 below shows the renewable energy technologies' in respect of capacity in India [2].

Wind energy, like many other renewable energy

"Corresponding author. resources, does not release any atmospheric emissions while generating power but at the same time there are some negative impacts to both the society and ecology. Many researchers have been working on various aspects of wind energy for more economic benefits, site selection procedures, environmental impacts, etc. Evaluation of wind energy systems using Geographical Information System (GIS) tool helps to understand the various

Table 1. Renewable energy technologies' respective capacity in India.

\begin{tabular}{cc}
\hline Source & Total Installed Capacity (MW) \\
\hline Wind Power & 19779.15 \\
Solar Power (SPV) & 1968.84 \\
Small Hydro Power & 3711.75 \\
Biomass Power & 1264.80 \\
Bagasse Cogeneration & 2337.43 \\
Waste to Power & 99.08 \\
Total & 29161.05 \\
\hline
\end{tabular}


aspects of a particular area. The present study aimed to analyse all aspects related to wind energy system of Gujarat state, India.

The State of Gujarat has the longest coast line in the country. Inland wind sites have an estimated potential of over 10,000 MW of Power. In India the wind generation capacity until April 2013 has reached about 3.11 GW [3]. 15 wind farm locations are shown in Table 2, most of which are located in western part of Gujarat. Over a period of 25 years, more than 65 sites have been monitored for wind speed and wind power density, out of which over 50 sites have been found feasible for harnessing the Wind Power by Gujarat Energy Development Agency (GEDA).

To evaluate the site suitability for wind turbines, the framework predictions are based on human, physical and environmental factors that influence the placement. For example, human factors are based on the proximity to development, public recreational area and agricultural land; physical factors are based on the wind resource and the proximity to sub-station and terrain, and the environmental factors depend on the land use, vegetation, wetlands, national parks etc.

\section{Methodology}

\subsection{Study Area}

The study area is of Gujarat state located on the western

Table 2. The table shows the wind generation capacity until 2011 and per annum capacity of single wind turbine [3].

\begin{tabular}{|c|c|c|c|c|}
\hline $\begin{array}{l}\text { Code } \\
\text { No }\end{array}$ & $\begin{array}{l}\text { Name of the wind } \\
\text { farm location }\end{array}$ & $\begin{array}{l}\text { No of } \\
\text { Turbine }\end{array}$ & $\begin{array}{l}\text { Installed } \\
\text { capacity }\end{array}$ & MW/turbine \\
\hline 1 & Bhuj & 34 turbines & $51 \mathrm{MW}$ & 1.50 \\
\hline 2 & Badi & 5 turbines & $4 \mathrm{MW}$ & 0.80 \\
\hline 3 & Umrala & 31 turbines & $25 \mathrm{MW}$ & 0.80 \\
\hline 4 & Suthri & 2 turbines & $10 \mathrm{MW}$ & 5.00 \\
\hline 5 & Ratdi & 1 turbine & $1 \mathrm{MW}$ & 1.00 \\
\hline 6 & Rajkot & 35 turbines & $53 \mathrm{MW}$ & 1.51 \\
\hline 7 & Navagam & 12 turbines & $10 \mathrm{MW}$ & 0.83 \\
\hline 8 & Kutch & 2 turbines & $2 \mathrm{MW}$ & 1.00 \\
\hline 9 & Kandla & 10 turbines & $21 \mathrm{MW}$ & 2.10 \\
\hline 10 & Bhavnagar & 4 turbines & $5 \mathrm{MW}$ & 1.25 \\
\hline 11 & Visavadar & 2 turbines & $2 \mathrm{MW}$ & 1.00 \\
\hline 12 & Bhogat & 7 turbines & $9 \mathrm{MW}$ & 1.28 \\
\hline 13 & Shikarpur & 1 turbine & $2 \mathrm{MW}$ & 2.00 \\
\hline 14 & Jamnagar \& Rajkot & 12 turbines & $10 \mathrm{MW}$ & 0.83 \\
\hline 15 & Lathedi & 6 turbines & $9 \mathrm{MW}$ & 1.50 \\
\hline
\end{tabular}

part of India between $20^{\circ} \mathrm{N}-24^{\circ} \mathrm{N}$, to $68^{\circ} \mathrm{E}-74^{\circ} \mathrm{E}$ in Figure 1 as obtained from GEDA. The area nearly covers 196024 sq. km with 26 districts . In this area, wetland covers $2113.86 \mathrm{sq}$. km, agriculture $93967.60 \mathrm{sq}$. km, urban land 1981.85 sq. km etc. The western part of Gujarat has $1915.29 \mathrm{~km}$ long coastline covering the Arabian Sea [4]. The elevation is between 0 to $1050 \mathrm{~m}$. The wind potential for Gujarat state is shown in Figure 2 as obtained from United Nation Development Program (UNDP) Wind Zone map as of 2006 [5]. As can be seen from Figure 2 the eastern part has less wind energy potential as compared to the western part.

\subsection{Database Development}

Multiple variables such as human, physical and environment factors are included in the geographical model for assessment of wind turbine site suitability. Data belonging to each of these factors are converted from vector to raster format. Later, it is re-sampled to $2 \times 2 \mathrm{~km}$ cell size. Finally all the data are converted to $2 \mathrm{~km}$ resolution for the overlay analysis using the fuzzy logic.

Fuzzy logic is a form of many-valued logic. It deals with reasoning and approximate, rather than fixed and exact values. Compared to traditional binary sets (where variables may take on true or false values) fuzzy logic variables may have a truth value that ranges in degree between 0 and 1 [6]. An example has been explained later in the Section 2.4.1.

The wind data is downloaded from climate research unit [7]. The wind speed at a height of $10 \mathrm{~m}$ with horizontal resolution of $2 \mathrm{~km}$ is used in our study. The digital elevation data is downloaded from global land cover faculty [8] with horizontal resolution of 90 meter. The land use and land cover data of 2009 are downloaded from European space agency [9]. As mentioned before these

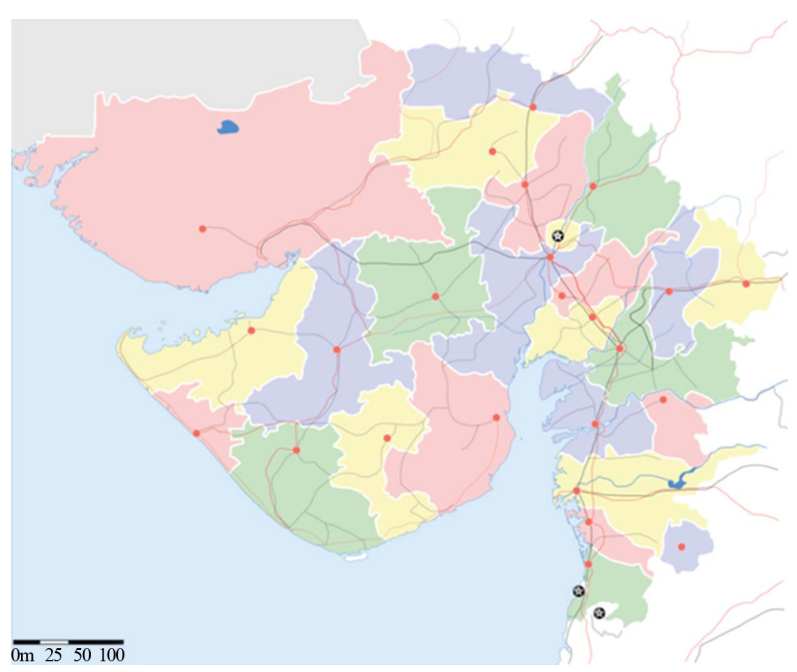

Figure 1. The map of Gujarat showing all the districts, major roads and rail network [4]. 

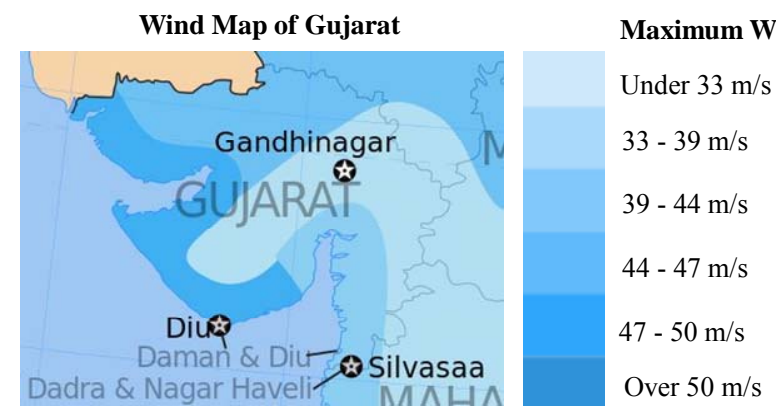

Figure 2. Wind zone map of Gujarat from UNDP wind zone map [5].

data are converted to $2 \mathrm{~km}$ resolution for overlay analysis. Finally, the location details of electrical substation data are collected from Gujarat Electricity Transmission Company (GETCO), the electricity transmission company of Gujarat for electricity off-take.

\subsection{Model Development}

To predict the suitable site for wind turbines, a model based on fuzzy logic has been developed and the flowchart of the same has been presented in the Figure 3 . From the results GIS model has been developed and evaluated. From the evaluations, the advantages and disadvantages at various geographical locations are analyzed. First, all the human, physical and environmental factors are identified based on the studies carried out by Rodmana, Meentemeyer and Aydin [10,11]. For environment factors wetland, natural reserves, water bodies and forest cover have been considered. For physical factors wind speed, slope and electrical substations have been considered and for human factors urban built up and agricultural areas have been considered. The morphological features in the study area are considered with spatial distribution of vector data. For example boundaries, water bodies, forest areas, agricultural areas, national parks, urban and rural areas, sub-stations etc. The raster slope data are collected and processed to obtain spatial data layers.

\subsection{Representation of Environmental, Physical and Human Factors as Fuzzy Sets}

\subsubsection{Fuzzy Sets}

In mathematics a set, by definition, is a collection of things that belong to some definition. Any item either belongs to that set or does not belong to that set. Let us look at another example [12]; the set of tall men. We shall say that people taller than or equal to 6 feet are tall. This set can be represented graphically in Figure 4 as follows:

The function shown above describes the membership of the "tall" set, you are either in it or you are not in it. This sharp edged membership functions works nicely for binary operations and mathematics, but it does not work as accurately in describing the real world. The membership function makes no distinction between somebody who is 6'1" and someone who is 7'1", they are both simply tall. Clearly there is a significant difference between the two heights. The other side of this lack of distinction is the difference between a 5'11" and 6' man. This is only a difference of one inch; however this membership function just says one is tall and the other is not tall.

The fuzzy set approach to the set of tall men provides a much better representation of the tallness of a person. The set, shown below in Figure 5, is defined by a continuously inclining function.

The membership function defines the fuzzy set for the possible values underneath of it on the horizontal axis. The vertical axis, on a scale of 0 to 1 , provides the membership value of the height in the fuzzy set. So for the two people shown above the first person has a membership of 0.3 and so is not very tall. The second person has a membership of 0.95 and so he is definitely tall. He does not, however, belong to the set of tall men in the way that bivalent sets work; has a high degree of membership in the fuzzy set of tall men.

\subsubsection{Representation of Environmental, Physical and Human Factors}

As explained in Section 2.4.1 and the method presented in Figure 3, fuzzy logic has been applied in similar manner to different factors namely physical, environmental and human factors related to wind turbine placement.

The environmental, human and physical factors are represented as fuzzy sets to evaluate the wind energy. Individual satisfaction degrees of each location with respect to the identified environmental, human and physiccal factors are computed in GIS using membership functions. Most fuzzy sets are used to represent the criteria or objectives which do not have crisp boundaries usually due to non-availability of information about the criteria or objectives. Fuzzy sets include crisp (precise) sets that are characterized by membership functions. For a crisp (precise) set $A$, an element $x$ in the universe is either a member of the set $A$ or may not be a member. An ele- 


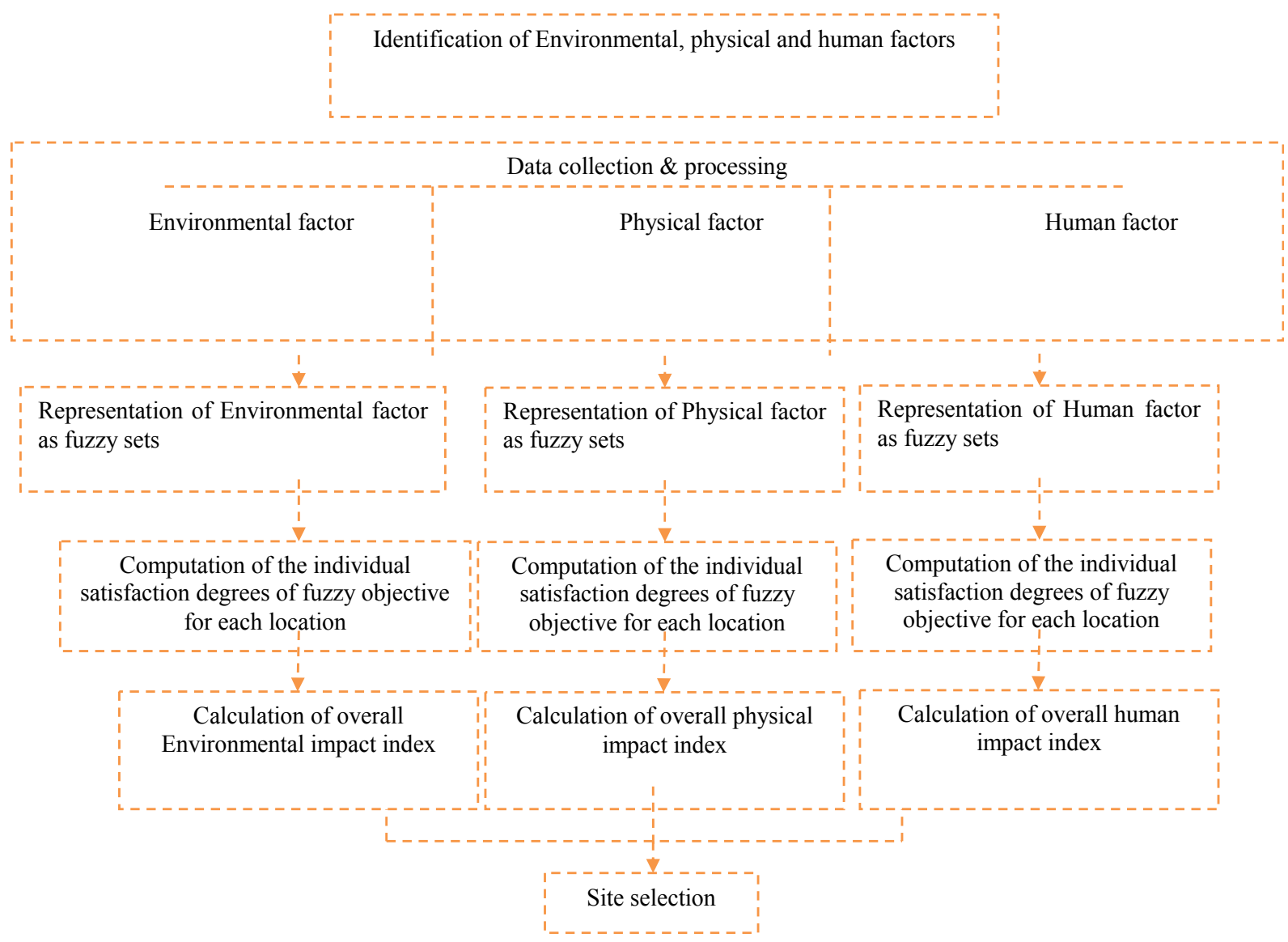

Figure 3. Flowchart of our model for site selection.

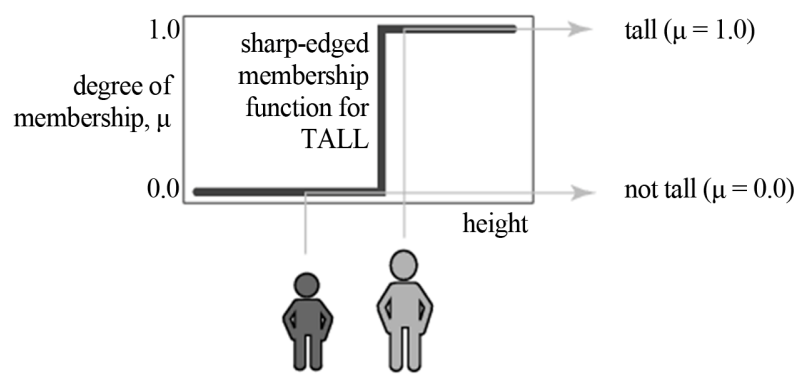

Figure 4. Hypothetical representation of Binary sets.

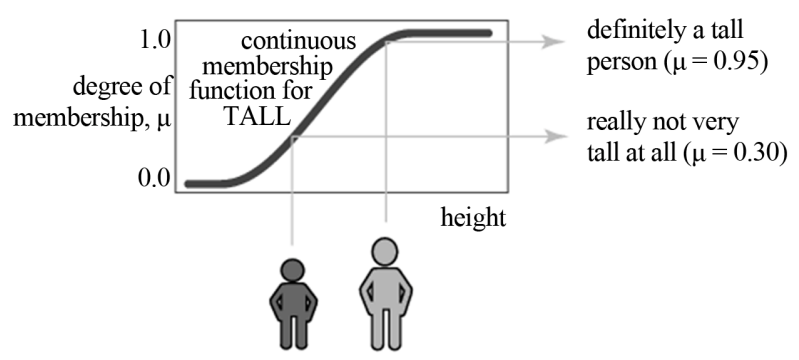

Figure 5. Hypothetical representation of fuzzy sets.

ment is a member, then its value is assigned as unity and if an element is not a member its value is assigned as " 0 ".
This is like a binary number. Mathematical function of this binary membership can be represented as:

$$
\begin{aligned}
& X_{a}(x)=\{1, x \in A\} \\
& X_{a}(x)=\{0, x \notin A\}
\end{aligned}
$$

where $X_{a}(x)$ indicates an explicit membership of an element $x$ in set $A$ and the symbol indicates the member is "contained in" and the symbol $\notin$ indicates that the member is "not contained in". The membership value " 0 " indicates no membership and the value " 1 " indicates full membership similar to that of a crisp (binary) set. Thus if the value of membership is unity means the higher grade of membership and zero or nil means data doesn't exist. The difference between the crisp and fuzzy set is that an element in a set can be represented by an infinite number of values between " 0 " and " 1 " in fuzzy sets, while it can only be represented by a zero or one in the crisp sets (binary sets).

The degree of compatibility of the function (i.e. location) with respect to each factor environmental, physical and human is determined by using the membership functions of the fuzzy sets associated with one of this factor. The degree of compatibility is referred as the individual satisfaction degree. For example in Figure 6, the dis- 
tance of environment factor (water body) is shown as a function of membership value. If the water body is very close, then the membership value is " 0 " and if it is more than $500 \mathrm{~m}$, the value is " 1 ". The membership value varies from 0 to 1 , depending on the distance as shown in Figure 6.

\section{5. “AND” Operator}

In fuzzy logic, there are various operators as per the requirement of the problem such as "OR", "AND", "SUM", "NOT" etc. In the following, more details are provided on "AND" operator as this operator is used in our present study.

The "AND" operator helps the decision makers, who desires satisfaction with many criteria. For a situation of two or more criteria to be considered T-norm operator is used. T-norm operators enable implementation of fuzzy set aggregation. It is noted by $[13,14]$ that $\mathrm{T}$-norm is a way to find Pareto optimal solution, because of its monotonic properties. Pareto Optimal Solution is one where in order to improve one criterion; at least one out of other many criteria must get worse. In product design, the Pareto surface is the mathematical embodiment of all possible optimal solutions. Thus, the mathematics of optimization focuses on finding solutions close to this $\mathrm{Pa}$ reto surface. In other words, if one of the parameter has a zero satisfaction degree, evaluation of overall satisfaction returns to zero, For instance, if the decision maker wants to consider many parameters with different criteria and satisfy all the ' $n$ ' criteria, then this can be represented by:

$$
D=f_{1} \cap f_{2} \cap \cdots f_{n}
$$

$D$ is the overall satisfaction and the bar sign on capital letters $f_{1}, f_{2} \ldots f_{\mathrm{n}}$ represent fuzzy sets. The following

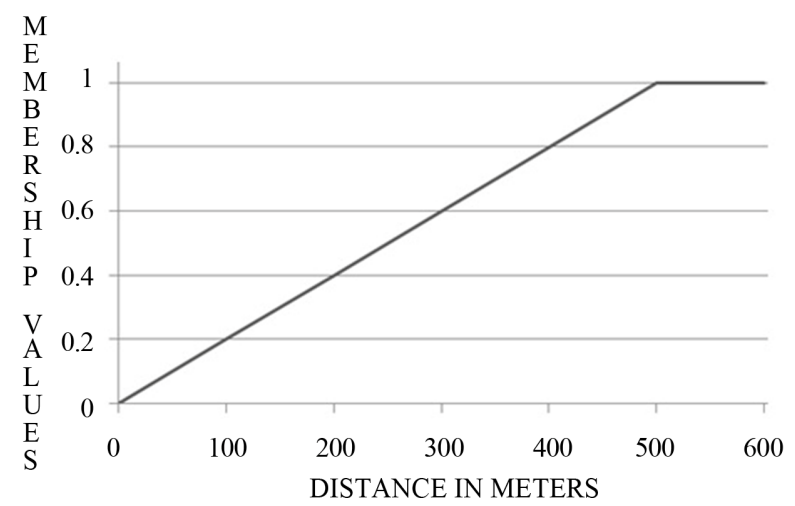

Figure 1. Representation of factors as fuzzy sets. The distance of environmental factor (water bodies) is shown as function of membership value. It the water body is very close, then the membership value is " 0 " and if it is more than $500 \mathrm{~m}$, the value is " 1 ". theorem expresses the important property of T-norm operator. Considering "T" corresponds to the T-norm operator, then for any value of criteria $a$ and $b$ such that $T$ $(a, b) \leq \operatorname{Min}(a, b)$. Implementation of "AND" operator allows no compensation for one or more parameters in Multi-Criteria Decision Making (MCDM) [15].

\subsection{Site Selection Approach}

As discussed in earlier sections, the individual satisfaction degree is based on environmental, human and physical parameters associated with each location. They are aggregated into a single value based on overall satisfaction degree using aggregator such as "AND" operator. Using the above logic, environmental impact index (Figure 7), physical impact index (Figure 8) and human impact index (Figure 9) are computed. Finally, aggregating the individual index of environmental, human and physical factor overall satisfaction index is prepared for the state of Gujarat and presented in Figure 10.

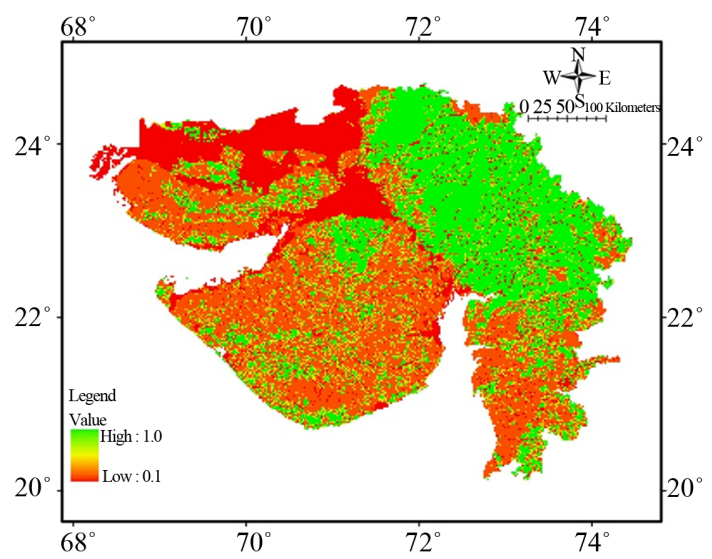

Figure 7. The map shows the suitable site in term of environmental factor. The colour green depicts high membership value and red colour depicts low membership value.

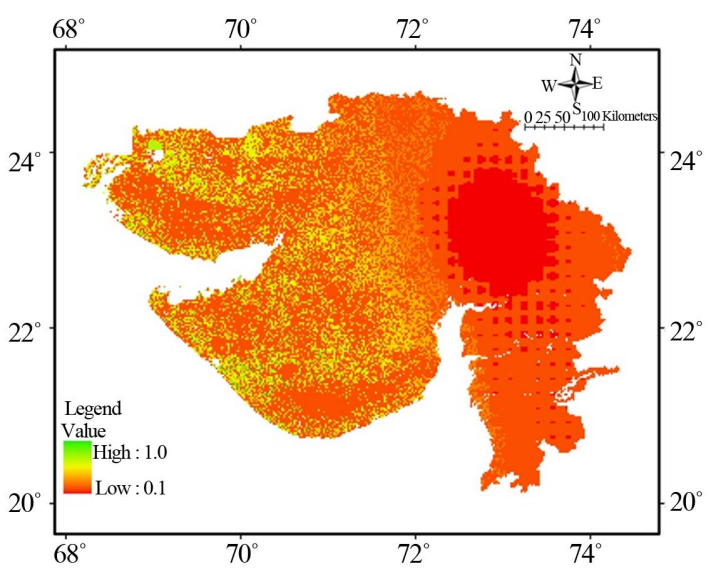

Figure 8. The map shows the suitable site in term of physical factor. The colour green depicts high membership value and red colour depicts low membership value. 


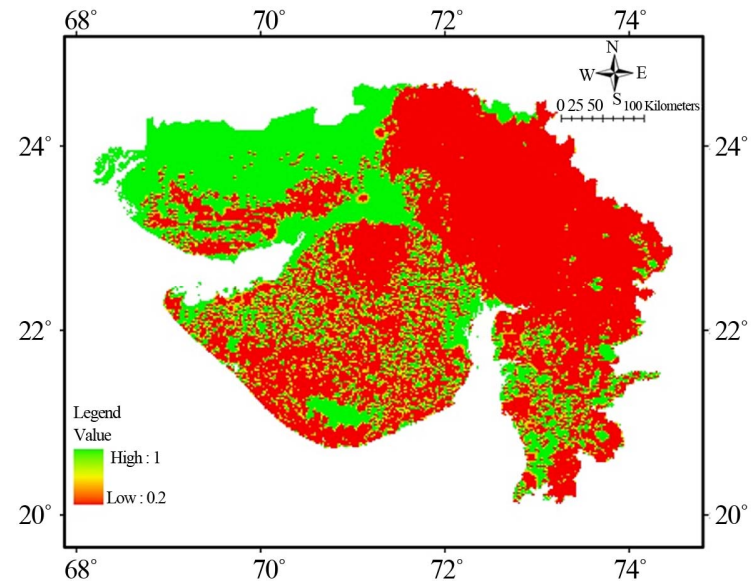

Figure 9. The map shows the suitable site in term of human factor. The colour green depicts high membership value and red colour depicts low membership value.

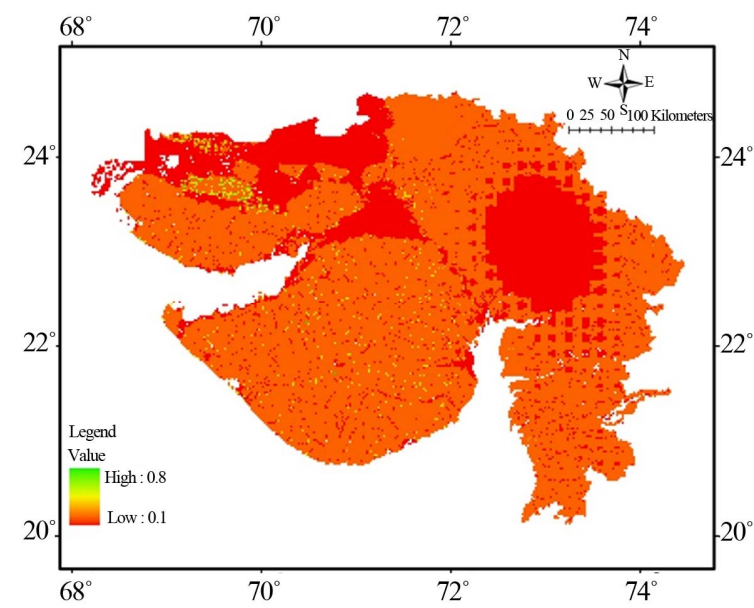

Figure 10. The overall performance index map shows suitable site in term of environmental physical and human factor. The colour green depicts high membership value and red colour depicts low membership value.

After preparation of overall performance index map based on environmental, human and physical parameters for the entire area of Gujarat state, we need to identify the priority locations based on threshold value. By ensuring different threshold values, different maps can be prepared. In Figure 10 we have assumed the threshold value of 0.6 and above. As can be seen there are more than 100 sites which satisfy the 0.6 threshold value. Additionally it is interesting to observe that all the locations are situated towards western part of Gujarat. Finally, the locations with overall performance index of 0.6 or higher are identified as priority site locations as per our study as present in Figure 11.

\section{Results}

The results derived from our study as per the fuzzy logic model obtained in Figure 11 have been described considering each parameter separately. The environmental parameter for suitability of wind turbine is considered. The highest suitability appears to be located towards north-eastern part of Gujarat and some pockets of Rajkot, Surat districts as shown in Figure 7. Next the physical model parameters for suitability of wind turbine are presented which includes sufficient wind speed, low-slope terrain and nearer to sub-station location as shown in Figure 8. As can be seen, the western part of Gujarat, mainly Kachchh, Jamnagar, Bhavnagar, Rajkot and Porbandar are appeared to be the preferred districts. The eastern part of Gujarat shows low potential zone. The threshold value, as described earlier has been kept 0.6. Finally, the human factor model for suitability of wind turbine is considered and presented in Figure 9. This model shows the suitability in areas that are neither agricultural nor human settlements, with a threshold value of 0.6 as before. Here one can see the preferred location is the Kachchh district.

The results derived from the present study are compared with actual wind farms installed in Gujarat. The current study reveals that many wind farm sites falls within the recommended area for placement of wind turbine (Figure 11) obtained from our model except four locations (bracketed values indicate no. of wind turbines), namely Badi (2), Umrala (3), Navagam (7) and Jamnagar and Rajkot combined (14). As can be seen from the Table 2, three wind turbine farms-Badi, Umrala, Nevagam - are producing less than $1 \mathrm{MW}$ per turbine. This result is in line with our predicted location. In view of above, the factors used in this GIS based site selection are very promising for suitable sites based on physical, environmental, and human parameters.

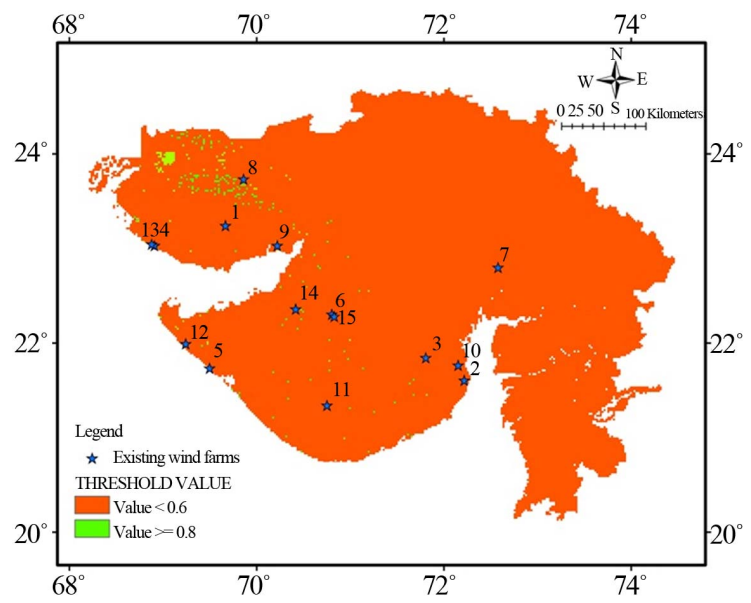

Figure 11. The map is showing priority sites within the study area. Most of them are located in the western part of Gujarat. More than 100 sites are identified to be placed at ideal locations as per the suitability of turbine placement results obtained from our model. 
Our study is aimed at considering all the three parameters, namely, the environment, the physical and the human factors. Accordingly in Figure 11, the preferred location for wind turbine potential is prepared by combination of all the three parameters with 0.6 threshold value. The total numbers of locations are about 100 and they are mostly present towards the western part of Gujarat.

\section{Summary and Conclusions}

This paper outlines the methodology for optimization in site selection for wind turbine placement using fuzzy logic and GIS technique by following a model presented in Figure 3. The suitability of placement is done considering different factors like physical, human and environmental aspects. Physical factors include wind speed, low slope proximity to an electrical sub-station for grid connection; environmental factors include wetland, water bodies, forest cover, natural reserves; human factors include factors like agricultural and human habitats. We have prepared the preferred location by considering each factor separately and finally covering all the three factors. We applied fuzzy logic criteria in arriving at the preferred location for a wind turbine.

In order to check the authenticity of the proposed model a comparison is done against all the existing wind turbines. It was found that almost 100 wind turbines are present at ideal locations at par with our proposed model. This proves the correct optimization approach of our model.

In conclusion, the rule-based suitability model objectively documents the various geographic factors that influence the location of wind turbines. This model will play a pivotal role in regulatory issues and planning and in carrying out their future work. Our model accurately depicts the locations and the coincidence of the existing wind farms at the recommended locations which are on interesting observation. This study would thus help to reduce the public repulsion, if any, over the wind turbine installations.

\section{Acknowledgements}

We would like to thank Prof. Anjana Vyas, Dean, Geomatics and Space Applications, CEPT University, Gujarat for her continuous encouragement. We also would like to thank Shri Tapan Ray, Vice Chairman and Managing Trustee, GERMI for the support to our study. We are grateful to GEDA and GETCO as well for providing us with necessary documents and figures which played an indispensible role while writing the paper.

\section{REFERENCES}

[1] Renew Indians, "Indian Renewable Energy Capacity Has
Reached 27.7 GW," 2013.

http://www.renewindians.com/2013/02/indian-renewableinstalled-capacity-has-reached-27.7GW.html

[2] MNRE, “Achievements, Ministry of New and Renewable Energy (MNRE), Government of India (GoI)," 2013.

http://www.mnre.gov.in/mission-and-vision-2/achieveme nts/

[3] GEDA, "Total Capacity Wind Power Projects Installed in Gujarat as of 30.04.2013," 2013.

http://geda.gujarat.gov.in/media/Wind_Power_Projects_C ompleted.pdf

[4] Gujarat from Wikipedia, "The Free Encyclopedia," 2013. http://en.wikipedia.org/wiki/Gujarat\#cite_note-wingsbird s.com-3

[5] United Nation Development Program (UNDP), "India Wind Zone Map," 2006.

http://upload.wikimedia.org/wikipedia/commons/thumb/5 /59/India_wind_zone_map_en.svg/1639px-India_wind_z one_map_en.svg.png

[6] V. Novák, I. Perfilieva and J. Močkoř, "Mathematical Principles of Fuzzy Logic,” Kluwer Academic, Dodrecht, 2005.

[7] M. Tim, "Table of Climate Grid and Derived Data Sets, Climate Data," Climate Research Unit (CRU), 2003. http://www.cru.uea.ac.uk/ timm/data/index-table.html

[8] Global Land Cover Faculty, "Global Land Survey Digital Elevation Model (GLSDEM)," 2013. http://www.glcf.umd.edu/data/glsdem/

[9] European Space Agency, “About,” 2013. http://www.esa.int

[10] L. C. Rodman and R. K. Meentemeyer, "A Geographic Analysis of Wind Turbine Placement in Northern California," Energy Policy, Vol. 34, No. 15, 2005, pp. 2137 2149.

[11] N. Y. Aydin, "GIS-Based Site Selection Approach for Wind and Solar Energy Systems: A Case Study from Western Turkey," Middle East Technical University, Inonu Bulvari, Ankara, 2009.

[12] Calvin, "Defining Fuzzy Sets," 2005. http://www.calvin.edu/ pribeiro/othrlnks/Fuzzy/fuzzysets .htm

[13] R. R. Yager, "Fuzzy Logic in the Formulation of Decision Functions from Linguistic Specifications," Kyberbêtes, Vol. 25, No. 4, 1996, pp. 119-130. http://dx.doi.org/10.1108/03684929610728069

[14] R. R. Yager, "Quantifier Guided Aggregation Using OWA Operators," International Journal of Intelligent Systems, Vol. 11, No. 1, 1996, pp. 49-73. http://dx.doi.org/10.1002/(SICI)1098-111X(199601)11:1 $<49:$ :AID-INT3>3.3.CO;2-L

[15] R. R. Yager, "On Ordered Weighted Averaging Aggregation Operators in Multi-Criteria Decision Making," IEEE Transactions on Systems, Man and Cybernetics, Vol. 18, No. 1, 1980, pp. 183-190. http://dx.doi.org/10.1109/21.87068 